\title{
Optimizing the management of uneven-aged Pinus nigra stands between two stable positions
}

\author{
Ignacio López Torres ${ }^{(1)}$, Sigfredo \\ Ortuño Pérez ${ }^{(1)}$, Fernando García \\ Robredo ${ }^{(1)}$, Carmen Fullana \\ Belda ${ }^{(2)}$
}

\begin{abstract}
This study proposes a discrete optimal control model to obtain harvest strategies that maximize the net present value (NPV) of the timber harvested from uneven-aged Pinus nigra stands located in the Spanish Iberian System, between two stable positions. The model was constructed using an objective function that integrates financial data on the harvesting operations with a matrix model describing the population dynamics. The initial and final states are given by the stable diameter distribution of the stand, and the planning horizon is $\mathbf{7 0}$ years. The scenario analysis corresponding to the optimal solutions revealed that the stand diameter distribution does not deviate substantially from the equilibrium position over time and that the NPV for the optimal harvesting schedule was always greater than the NPV for the "sustainable/stable" harvesting strategy. The NPV increase for the different scenarios is between $5.36 \%$ and $14.43 \%$, showing a greater increase in higher site index scenarios and higher recruitments.
\end{abstract}

Keywords: Sustainability, Stability, Equilibrium, Optimal Harvesting, Discrete Optimal Control, Matrix Model good way to reach and maintain that equilibrium with sustainability. In fact, the "sustainable/stable" harvesting strategy is aimed at reaching the stable diameter distribution of the stand for each harvest, yielding for all the diameter classes and time steps the following "sustainable/stable" harvest rate (eqn. 1):

$$
s=\frac{\lambda_{o}-1}{\lambda_{o}}
$$

where $\lambda_{0}$ is the dominant eigenvalue of the transition matrix without harvests, and $s$ also includes the natural mortalities. This is a sustainable harvesting strategy too (in the sense of population persistence over time) because $s$ corresponds to the case such that the right eigenvector associated with the dominant eigenvalue $\lambda=1$ of the transition matrix with harvests, is $W_{0}$.

By contrast, many harvesting strategies do not satisfy the requirements of sustainability or stability. In fact, using an objective function that integrates financial data
(1) Universidad Politécnica de Madrid (UPM), ETSI de Montes, Ciudad Universitaria, E28040 Madrid (Spain); (2) Universidad Pontificia de Comillas, Alberto Aguilera 23, E-28015 Madrid (Spain)

@ Ignacio López Torres (i.lopez@upm.es)

Received: Mar 26, 2014 - Accepted: Nov 05, 2015

Citation: López Torres I, Ortuño Pérez S, García Robredo F, Fullana Belda C (2016). Optimizing the management of uneven-aged Pinus nigra stands between two stable positions. iForest 9: 599-607. - doi: 10.3832/ifor1298-008 [online 2016-03-01]

Communicated by: Agostino Ferrara of harvesting operations with a matrix model to describe the population dynamics, a posed by López et al. (2013) showed that the economically optimal harvesting strategies underlying the solutions of that model changed the stand towards distributions more characteristic of even-aged stands and substantially deviated from the stable diameter distribution. Moreover, the corresponding economically optimal harvesting strategies were always unsustainable, in the sense that the population growth rate $\lambda_{T}$ for the whole harvest cycle was always $\lambda_{T}$ $<1$, being $\lambda_{T}$ the dominant eigenvalue of the transition matrix from $t=0$ to $t=T$, and $T$ the planning horizon.

This study investigates the existence of a new sustainable, stable, and economically optimal harvesting strategy for unevenaged Pinus nigra stands in the Spanish Iberian System. We rely on an objective function that integrates financial data of harvesting operations with a matrix model that describes the population dynamics, which creates a discrete optimal control model. In addition, it is investigated whether the sustainability and stability conditions can be satisfied by assuming the stable diameter distribution of the stand as the initial and final conditions, that is $X(0)=$ $X(T)=W_{0}$. Furthermore, we examine the effects of diameter growth, stand density, and recruitment on those strategies, considering a wide variety of typical management scenarios in the study area, obtained by combining three rates of diameter growth, three levels of stand basal area ( $G$ $=22,24$, and $26 \mathrm{~m}^{2}$ ha-1), and three levels of global recruitment (scarce: $R=200$ stems recent discrete optimal control model pro- 
ha ${ }^{-1}$; normal: $R=520$ stems ha ${ }^{-1}$; and abundant: $R=840$ stems ha ${ }^{-1}$ ). Finally, an economic comparison has been performed between this economically optimal harvesting strategy between two stable positions and the "sustainable/stable" strategy for each scenario.

In general, optimal control theory enables the solution of a wide variety of dynamic problems, for which the evolution of the dynamic system (discrete or continuous) can be partially controlled by the agent's decision. In every moment $t$, the system can be described by a set of state variables $x_{\mathrm{k}}(t)$ (e.g., stems ha-1 in diameter class $k$ at year $t$ ), so the manager chooses a specific set of control variables $h_{\mathrm{k}}(t)$ (e.g., harvest rate in diameter class $k$ at year $t$ ). Different values for the control variables imply different paths in the phase space for the dynamic system and the manager must determine the control values that maximize the selected objective, according to the constraints of the problem.

Many authors have considered optimal control theory to model forest stands management both in continuous case (Haight 1985, Sethi \& Thompson 2000) and in discrete case (Kronrad \& Huang 2002, Tahvonen 2004, López et al. 2010, 2013).

In the following sections, we describe the model and the estimates of the corresponding parameters. The general calculations, including regressions, employed the software Maple (2014) version 18, and the solutions to the optimization problems were derived using the Solver ${ }^{\otimes}$ tool running under MS Excel $2013^{\circledR}$.

\section{Materials and methods}

\section{Discrete optimal control model}

This model has three main features: (1) an underlying discrete time dynamic system, given by the stand population dynamics; (2) an objective function, which is in this case the net present value (NPV) of timber income over a fixed time horizon $\mathrm{T}$; and (3) a set of constraints.

The combination of the objective function with the population dynamics model and the constraints produces a discrete optimal control problem, from which we have to determine control variables $h_{\mathrm{k}}(t)$ that globally maximize the function NPV subject to the population dynamics and constraints.

\section{Stand population dynamics}

The stands of the study area are located in the Spanish Iberian System, a mountain range extending about $400 \mathrm{~km}$ along the north-eastern edge of the Central Plateau, including $60 \%$ of the area occupied by Pinus nigra in Spain (Grande \& García Abril 2005). The management of Pinus nigra stands in this area is currently based on the growth and yield tables for Pinus nigra Arn. in the Spanish Iberian System (Gómez Loranca 1998). The data in these tables are classified according to growth rates into five site qualities, of which only the first three have been selected as our data source. These three qualities were defined by the dominant heights reached at the reference age of 60 years (20,17, and $14 \mathrm{~m}$, respectively). The study area is very large, covering the whole range of $P$. nigra in the Spanish Iberian System. Therefore, the spectrum of values taken by environmental variables such as slope, soil type, and even climatic characteristics is also very wide. This variability is captured in the growth and yield tables used by considering different site qualities that reflect variations in topography, height, slope, aspect, weather, and vegetation.

The population dynamics model that integrates recruitment, harvesting, and stem migration throughout the diameter classes over time is based on the model proposed by López et al. (2007, 2008) for Fagus sylvatica L., and by López et al. (2012, 2013) for Pinus nigra Arn. stands.

The starting assumptions were as follows: (a) the forest is in a steady state; (b) the average diameter growth curves for site indices 20 to 14 are defined by the Bertalanffy-Richards model (Von Bertalanffy 1938, Richards 1959); (c) within each diameter class, the probability distribution for the diameter of the trees is uniform (rectangular); and (d) harvesting operations occur at the beginning of every projection interval. Group selection cutting is the silvicultural system used because $P$. nigra is not a shade-tolerant species, and the gaps opened in the canopy through single-tree selection cutting would not be large enough to ensure regeneration.

Harvesting operations in the study area generally take place every 10 years, thus we adopted this period as the range of the projection intervals in the model. Considering this time period and the diameter growth functions corresponding to site indices 20 to 14 , trees were grouped into $n$ diameter classes of equal width $w=6 \mathrm{~cm}$ : $0-6,6-12,12-18, \ldots, 30-36, \ldots$, with the last class being more than $48 \mathrm{~cm}(48, \rightarrow)$ for site index 20 , more than $42 \mathrm{~cm}(42, \rightarrow)$ for site index 17 and more than $36 \mathrm{~cm}(36, \rightarrow)$ for site index 14 (note that $n=9$ for site index $20, n=8$ for site index 17, and $n=7$ for site index 14). Therefore, an individual tree in class $k$ can remain in class $k$ or progress to class $k+1$ during the projection interval $(t, t+10)$. The number of trees in each class changed for each projection interval because some were harvested, some remained in the same diameter class, and others grew past the boundary to the next diameter class. In such conditions, $p_{\mathrm{k}}$ refers to the probability that an individual tree in class $k$ at time $t$ will appear in class $k$ +1 at time $t+10$. The term $r_{\mathrm{k}}$, or recruitment coefficient, is the number of offspring (stems ha ${ }^{-1}$ ) living at time $t+10$, produced in the interval $t, t+10$ by an average tree in class $k$ at time $t$. Similar to many standard size classified matrix models, we did not consider the smallest diameter class to be fertile (Caswell 2001). The variable $h_{\mathrm{k}}(t)$ defines the proportion of harvested trees in class $k$ at year $t$, natural mortality included. Finally, $x_{\mathrm{k}}(t)$ and $x_{\mathrm{k}}(t+10)$ describe the stem densities in class $k$ at the initial and final projection times. By analysing the dynamics of the projections, we find that the model is described accurately by the following matrix model (eqn. 2):

$$
X(t+10)=A[I-H(t)] X(t)
$$

where (eqn. 3):

$$
A=\left(\begin{array}{cccccc}
1-p_{1} & r_{2} & r_{3} & \ldots & r_{n-1} & r_{n} \\
p_{1} & 1-p_{2} & 0 & \ldots & 0 & 0 \\
0 & p_{2} & 1-p_{3} & \ldots & 0 & 0 \\
\vdots & \vdots & \vdots & \ddots & \vdots & \vdots \\
0 & 0 & 0 & \ldots & 1-p_{n-1} & 0 \\
0 & 0 & 0 & \ldots & p_{n-1} & 1
\end{array}\right)
$$

and $I$ is the identity matrix; $H(t)=\operatorname{diag}\left[h_{1}(t)\right.$, $\left.h_{2}(t), \ldots, h_{\mathrm{n}}(t)\right]$ is a diagonal matrix with the harvest rates $h_{\mathrm{k}}(t)$; and $X(t)$ and $X(t+10)$ are column vectors indicating the stem densities at the initial and final times of projection, respectively.

\section{Objective function}

Considering that the main goal for the stands in the study area is the production of timber, the objective function of the optimization problem is the NPV of all management operations over a planning horizon of $T=70$ years, discounted to the beginning of the period and from the landowner's perspective, that is (eqn. 4):

$$
\begin{aligned}
N P V= & \sum_{k=1}^{n} \sum_{t=0}^{T-10} x_{k}(t) h_{k}(t) v_{k}(t) \frac{1}{(1+i)^{t}}+ \\
& \sum_{k=1}^{n} x_{k}(T) v_{k}(T) \frac{1}{(1+i)^{T}}
\end{aligned}
$$

where $v_{\mathrm{k}}(t)$ is the stumpage value that corresponds to class $k$ at year $t(\epsilon /$ stem) and $i$ is the discount rate. The first summation represents the income derived from timber sale and the second is the final stocking value. It is well known that the NPV is a justifiable management objective for a single economic goal (Siegel et al. 1995).

Harvesting costs are not considered because harvesting operations are not paid by the owner. The costs for the owner of the land are the opportunity cost of the invested capital and the opportunity cost of the land. None of them are explicit costs, but they are incorporated into the NPV obtained. This hypothesis is not restrictive since active forest management in the Mediterranean area is not frequent and the owner does not invest any effort in silvicultural actions.

The cost of harvesting operations would be paid by the buyer of the stumpage and that is the reason we did not consider it in the present study.

\section{Set of constraints}

As mentioned above, the initial and final conditions must represent the stable diameter distributions of the stand $W_{0}$. There- 
fore, the first constraints are given by (eqn. 5):

$$
X(0)=X(T)=W_{0}
$$

We also set the following obvious constraints (eqn. 6):

$$
m_{k} \leq h_{k}(t) \leq 1
$$

for $k=1,2, \ldots, n$ and $t=0,10,20,30, \ldots, T$ 10 , where $m_{\mathrm{k}}$ is the natural mortality in $k$-th class.

On the other hand, by applying the "sustainable/stable" harvesting strategy to each scenario and setting $X(0)=W_{\mathrm{o}}$ as the initial condition, the basal area of the stand continuously oscillates between values $G_{\text {min }}$ (after harvesting) and $G_{\max }$ (before harvesting), and the stable diameter distribution is reached at each time step. Therefore, to compare the economically optimal and the "sustainable/stable" harvesting strategies, it is essential to assume an additional constraint to maintain the stand basal area throughout the harvest cycle within the range $G_{\min }-G_{\max }$ during the optimization process, where $G_{\max }$ was 22,24 , and 26 for the three levels $G=22,24$, and $26 \mathrm{~m}^{2} \mathrm{ha}^{-1}$, respectively, and $G_{\min }$ is the minimum basal area reached for each scenario under the "sustainable/stable" harvesting strategy.

\section{Optimization method}

For each discount rate, the tool Solver ${ }^{\oplus}$ of MS Excel $2013^{\circledast}$ was used to obtain a globally optimal solution of these nonlinear models by applying multistart methods. These methods provide a "convergence in probability" to a globally optimal solution, which means that as the number of runs of the nonlinear Solver routine increases, the probability that the globally optimal solution has been found also increases towards $100 \%$.

The control variables $h_{\mathrm{k}}(t)$ that maximize the objective function NPV (always under the population dynamics and the constraints mentioned above) are the solutions to the corresponding problem (one optimal solution for each scenario). Finally, the optimal harvesting schedules are defined by the combination of the control variables $h_{\mathrm{k}}(t)$ corresponding to the scenario analyzed.

\section{Input estimation}

\section{Transition probabilities}

We calculated the transition probabilities by applying the method introduced in López et al. (2012) considering that, given the basal area constraints and the low basal area scenarios of this study, stand density has a small influence on diameter growth. Thus, the diameter growths were defined by the Bertalanffy-Richards function (Von Bertalanffy 1938, Richards 1959 eqn. 7 ):

$$
D=f(t)=a\left(1-e^{-b t}\right)^{c}
$$

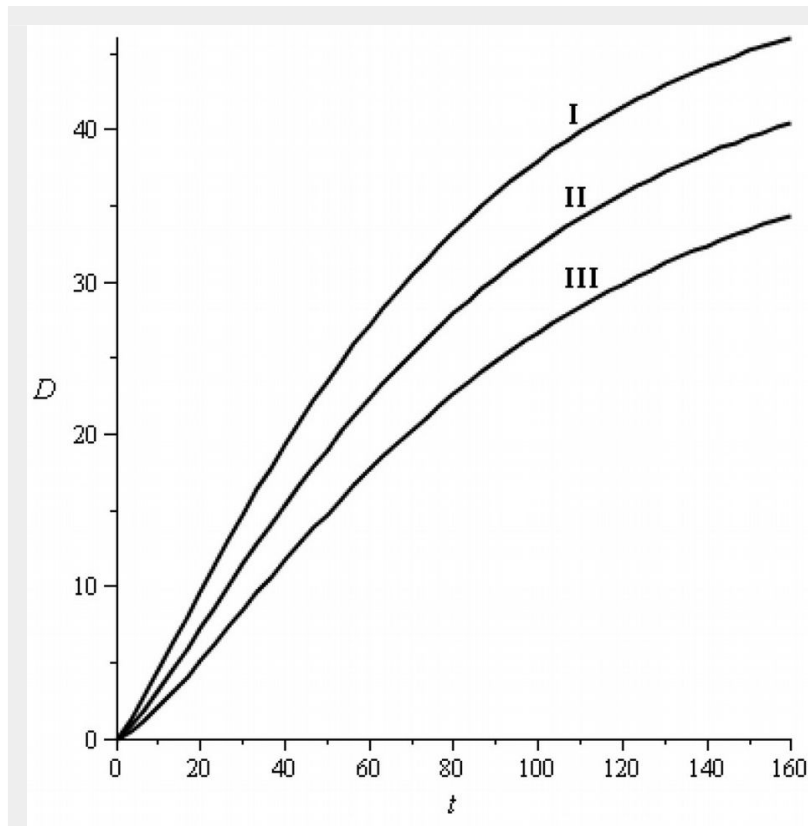

Fig. 1 - Diameter growth models (dbh $D$ in $\mathrm{cm}$ and time $t$ in years).

I: Site index 20, $D=51.68$ $\left(1-\mathrm{e}^{-0.015259}\right)^{1.255111}$; II: Site index 17, $D=46.645633$ $\left(1-\mathrm{e}^{-0.014318 \mathrm{t}}\right)^{1.337062}$; III: Site index $14, D=40.644134$ $\left(1-\mathrm{e}^{-0.013838 \mathrm{t}}\right)^{1.456382}$. The coefficient of determination was always greater than 0.999 . adjusted using regression analysis to data points $[t, D(t)]$ obtained from tables by Gómez Loranca (1998). The main characteristics of these growth models are shown in Fig. 1.

Using these diameter-growth models, the transition probabilities from class $i$ to class $(i+1)$ or from interval $[6(i-1), 6 i]$ to interval $[6 i, 6(i+1)]$ are given by (eqn. 8$)$ :

$$
p_{i}=\frac{f\left[f^{-1}(6 i)+10\right]-6 i}{f\left[f^{-1}(6 i)+10\right]-f\left[f^{-1}(6(i-10))+10\right]}
$$

for $i=1,2,3,4, \ldots, n-1$, where $f^{-1}$ is the inverse function of $f$ in eqn. 7 defined as (eqn. 9):

$$
f^{-1}(D)=-\frac{1}{b} \log \left[1-\left(\frac{D}{a}\right)^{1 / c}\right]
$$

where $t$ is the age in years and $D$ is the dbh in $\mathrm{cm}$.

The above-mentioned transition probability equation is a direct application of the formula introduced by López et al. (2007, 2008) for a Bertalanffy-Richards model. We provide the calculations for site indices 20 , 17, and 14 in Tab. 1.

According to the model assumptions and the methodology used, we had to consider that the same transition probability $p_{k}$ applies to all of the individuals in the same class $k$ (where there might exist individuals under very different conditions), i.e., the transition probability $p_{\mathrm{k}}$ is a global property shared by all of the individuals in the same class $k$, independently of their local conditions. We consider that the stratification into three site index classes must result in low variability around the mean $p_{\mathrm{k}}$ values.

\section{Recruitment and basal area}

Pinus nigra regenerates well under its own canopy (Retana et al. 2002, Tíscar 2007), and recruitment may be very abundant even at high densities, as described by Tíscar Oliver et al. (2010) who reported

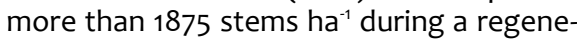
ration event in Pinus nigra stands with $G=$ $51.96 \mathrm{~m}^{2} \mathrm{ha}^{-1}$. Nonetheless, there is a critical basal area for sufficient light transmittance for regeneration, approximately $20-30 \mathrm{~m}^{2}$ ha $^{-1}$ (Schütz 1989, Serrada et al. 1994). Therefore, we have considered in the calculations three levels of stand basal area in that range, $G=22,24$, and $26 \mathrm{~m}^{2} \mathrm{ha}^{-1}$. With these basal area values, we assumed the same three levels of recruitment $(R)$ as in our previous studies: (i) 200 stems ha ${ }^{-1}$ (scarce recruitment); (ii) 520 stems ha $^{-1}$ (normal); (iii) and 840 stems ha ${ }^{-1}$ (abundant). For these cases, similar to other matrix models for tree species (Van Mantgem \& Stephenson 2005), we attributed the global amount of recruitment $R$ entirely to the
Tab. 1 - Transition probabilities $\left(p_{\mathrm{k}}\right)$ between diameter classes for each site index.

\begin{tabular}{lccc}
\hline Transition & Site index 20 & Site index 17 & Site index 14 \\
\hline$(0-6) \rightarrow(6-12)$ & $p_{1}=0.7697$ & $p_{1}=0.5951$ & $p_{1}=0.4564$ \\
$(6-12) \rightarrow(12-18)$ & $p_{2}=0.8602$ & $p_{2}=0.6824$ & $p_{2}=0.5326$ \\
$(12-18) \rightarrow(18-24)$ & $p_{3}=0.7913$ & $p_{3}=0.6200$ & $p_{3}=0.4697$ \\
$(18-24) \rightarrow(24-30)$ & $p_{4}=0.6828$ & $p_{4}=0.5190$ & $p_{4}=0.3692$ \\
$(24-30) \rightarrow(30-36)$ & $p_{5}=0.5533$ & $p_{5}=0.3971$ & $p_{5}=0.2475$ \\
$(30-36) \rightarrow(36-42)$ & $p_{6}=0.4106$ & $p_{6}=0.2618$ & $p_{6}=0.1119$ \\
$(36-42) \rightarrow(42-48)$ & $p_{7}=0.2587$ & $p_{7}=0.1171$ & - \\
$(42-48) \rightarrow(48, \rightarrow)$ & $p_{8}=0.1000$ & - & - \\
\hline
\end{tabular}


Tab. 2 - Numerical values for $\lambda_{0}, s$, and stable distributions ( $G$ in $\mathrm{m}^{2}$ ha ${ }^{-1}$, Est. Dis. in stems ha $\left.{ }^{-1}\right)$.

\begin{tabular}{|c|c|c|c|c|c|}
\hline Site Index & $G$ & Variable & $\begin{array}{c}R=200 \\
\text { stems ha-1 }\end{array}$ & $\begin{array}{c}R=520 \\
\text { stems ha }\end{array}$ & $\begin{array}{c}R=840 \\
\text { stems ha-1 }\end{array}$ \\
\hline \multirow[t]{10}{*}{20} & \multirow[t]{3}{*}{22} & $\lambda_{0}$ & 1.305091 & 1.477671 & 1.594240 \\
\hline & & $s$ & 0.233770 & 0.323259 & 0.372742 \\
\hline & & Est. Dis. & $\begin{array}{c}{[186.1,122.9,96.4,77.2} \\
61.4,47.5,34.6,22.1,7.2]\end{array}$ & $\begin{array}{l}{[416.9,239.8,162.6,110.9} \\
73.4,45.7,25.5,11.4,2.4]\end{array}$ & $\begin{array}{c}{[615.9,325.9,202.3,125.4} \\
74.6,41.1,19.8,7.4,1.2]\end{array}$ \\
\hline & \multirow[t]{3}{*}{24} & $\lambda_{0}$ & 1.292499 & 1.458959 & 1.571264 \\
\hline & & $G_{\min }$ & 18.568685 & 16.450081 & 15.274322 \\
\hline & & Est. Dis. & $\begin{array}{c}{[188.3,125.7,99.8,81.0} \\
65.4,51.4,38.3,25.3,8.6]\end{array}$ & $\begin{array}{l}{[423.2,246.9,169.9,117.8} \\
79.4,50.5,28.9,13.4,2.9]\end{array}$ & $\begin{array}{c}{[626.4,336.8,212.6,134.2} \\
81.5,45.9,22.7,8.8,1.5]\end{array}$ \\
\hline & \multirow[t]{4}{*}{26} & $\lambda_{0}$ & 1.281305 & 1.442342 & 1.550881 \\
\hline & & $s$ & 0.219546 & 0.306683 & 0.355205 \\
\hline & & $G_{\min }$ & 20.291808 & 18.026241 & 16.764668 \\
\hline & & Est. Dis. & $\begin{array}{c}{[190.3,128.3,102.9,84.5} \\
69.1,55.3,42.0,28.5,10.1]\end{array}$ & $\begin{array}{l}{[429.0,253.5,176.8,124.3} \\
85.3,55.3,32.4,15.5,3.5]\end{array}$ & $\begin{array}{l}{[636.1,347.0,222.4,142.6,} \\
88.2,50.8,25.7,10.2,1.9]\end{array}$ \\
\hline \multirow{11}{*}{17} & \multirow{3}{*}{22} & $s$ & 0.207665 & 0.292049 & 0.339704 \\
\hline & & $G_{\min }$ & 17.431369 & 15.574919 & 14.526515 \\
\hline & & Est. Dis. & $\begin{array}{c}{[233.3,147.0,113.7,90.3} \\
\quad 71.1,53.9,37.2,16.6]\end{array}$ & $\begin{array}{c}{[516.1,280.5,185.4,123.4} \\
\quad 79.1,46.6,23.0,6.5]\end{array}$ & $\begin{array}{c}{[757.0,376.4,226.4,135.8} \\
\quad 77.3,39.6,16.4,3.7]\end{array}$ \\
\hline & \multirow[t]{4}{*}{24} & $\lambda_{0}$ & 1.251140 & 1.396188 & 1.494358 \\
\hline & & $s$ & 0.200729 & 0.283764 & 0.330816 \\
\hline & & $G_{\min }$ & 19.182509 & 17.189656 & 16.060414 \\
\hline & & Est. Dis. & $\begin{array}{l}{[236.3,150.7,118.0,95.0} \\
\quad 76.1,58.9,41.9,19.5]\end{array}$ & $\begin{array}{c}{[524.6,289.4,194.4,131.7} \\
86.1,52.0,26.5,7.8]\end{array}$ & $\begin{array}{c}{[771.0,389.9,238.8,146.1} \\
\quad 85.0,44.7,19.1,4.5]\end{array}$ \\
\hline & \multirow[t]{4}{*}{26} & $\lambda_{0}$ & 1.241406 & 1.381684 & 1.476521 \\
\hline & & $s$ & 0.194462 & 0.276245 & 0.322732 \\
\hline & & $G_{\min }$ & 20.943989 & 18.817621 & 17.608961 \\
\hline & & Est. Dis. & $\begin{array}{l}{[239.1,154.0,122.0,99.5} \\
\quad 80.9,63.8,46.6,22.6]\end{array}$ & $\begin{array}{c}{[532.4,297.7,202.8,139.6} \\
93.0,57.4,30.1,9.2]\end{array}$ & $\begin{array}{c}{[783.9,402.5,250.5,156.0} \\
\quad 92.7,49.8,22.0,5.4]\end{array}$ \\
\hline \multirow[t]{10}{*}{14} & \multirow[t]{2}{*}{22} & $\lambda_{0}$ & 1.220604 & 1.350816 & 1.439536 \\
\hline & & $s$ & 0.180733 & 0.259707 & 0.305332 \\
\hline & \multirow[t]{4}{*}{24} & $\lambda_{0}$ & 1.211164 & 1.336630 & 1.422004 \\
\hline & & $s$ & 0.174348 & 0.251850 & 0.296767 \\
\hline & & $G_{\min }$ & 19.815651 & 17.955611 & 16.877591 \\
\hline & & Est. Dis. & $\begin{array}{c}{[299.6,183.8,143.8,116.4} \\
93.7,71.8,38.0]\end{array}$ & $\begin{array}{c}{[655.8,344.3,227.4,151.3} \\
95.6,52.8,17.6]\end{array}$ & $\begin{array}{c}{[956.3,457.2,273.0,162.1} \\
89.4,41.4,11.0]\end{array}$ \\
\hline & \multirow[t]{4}{*}{26} & $\lambda_{0}$ & 1.202780 & 1.324044 & 1.406468 \\
\hline & & $s$ & 0.168593 & 0.244738 & 0.288999 \\
\hline & & $G_{\min }$ & 21.616583 & 19.636810 & 18.486024 \\
\hline & & Est. Dis. & $\begin{array}{c}{[303.4,188.3,149.1,122.5} \\
100.4,79.0,43.6]\end{array}$ & $\begin{array}{c}{[666.3,355.0,238.2,161.4} \\
104.2,59.2,20.4]\end{array}$ & $\begin{array}{c}{[973.6,473.1,287.6,174.1} \\
98.3,46.9,12.9]\end{array}$ \\
\hline
\end{tabular}

last diameter class $\left(r_{2}=r_{3}=\ldots=r_{\mathrm{n}-1}=0 ; r_{\mathrm{n}}=\right.$ $\left.R /\left[x_{\mathrm{n}}(0)\right]\right)$, which had no influence on the stable diameter distribution of the stand, which is established by transition probabilities, global amount of recruitment, and stand basal area (López et al. 2007).

\section{Natural mortalities}

We estimated natural mortalities based on previous studies. Specifically, Misir et al. (2007) developed a mortality model for Pinus nigra subsp. pallasiana in Turkey from a logistic model and the observed data. They estimated an overall annual mortality rate of $1.41 \%$, equivalent to a $13.24 \%$ mortality rate in a 10-year period. Trasobares \& Pukkala (2004) studied Pinus nigra Arn. in north-eastern Spain and suggested natural mortality rates of $2 \%$ (including minimal intermediate thinning) for the $D>30 \mathrm{~cm}$ diameter classes. Therefore, the following 10- year individual tree constant mortality rates for each diameter class were assumed: $m_{1}=0.20 ; m_{2}=0.14 ; m_{3}=0.08 ; m_{4}=0.05 ; m_{5}$ $=0.03 ;$ and $m_{6}=m_{7}=\ldots=m_{\mathrm{n}}=0.02$.

\section{"Sustainable/stable" harvesting strategy. Stable diameter distribution}

As mentioned above, the "sustainable/ stable" harvesting strategy is aimed at reaching in each harvest the proportion of stems $\mathrm{ha}^{-1}$ in each class corresponding to the stable diameter distribution of the stand, yielding the following "sustainable/stable" harvest rate shown in eqn. 1 , for all of the diameter classes and time steps. This rate corresponds to the case such that the right eigenvector associated with the dominant eigenvalue $\lambda=1$ of the transition matrix with harvests is $W_{0}$ for each time step.

By applying the "sustainable/stable" har- vesting strategy to each scenario and setting $X(0)=W_{0}$ (stable diameter distribution) as the initial condition, the basal area of the stand continuously oscillates between the values $G_{\min }$ (after harvesting) and $G_{\max }$ (before harvesting), and the stable diameter distribution is reached at each time step. The calculations for the $27 \mathrm{sce}$ narios of this study, obtained by combining three rates of diameter growth with three levels of recruitment $(R=200,520$, or 840 stems ha-1), and three levels of stand basal area $\left(G=G_{\max }=22,24\right.$, or $\left.26 \mathrm{~m}^{2} \mathrm{ha}^{-1}\right)$, are shown in Tab. 2 along with the population growth rates $\lambda_{0}$, the "sustainable/stable" harvest rates $s$, and the minimum basal areas $G_{\min }$.

On the other hand, to compare the economically optimal and the "sustainable/stable" harvesting strategies, the NPV values corresponding to the "sustainable/stable" 
strategies are given by (eqn. 10):

$$
\begin{aligned}
N P V= & \sum_{k=1}^{n} \sum_{t=0}^{T-10} w_{k} s v_{k}(t) \frac{1}{(1+i)^{t}}+ \\
& \sum_{k=1}^{n} w_{k} v_{k}(T) \frac{1}{(1+i)^{T}}
\end{aligned}
$$

and the distance between these distributions can be evaluated with Keyfitz's $\Delta$ (eqn. 11):

$$
\Delta\left(X, W_{0}\right)=\frac{1}{2} \sum_{i=1}^{n}\left|x_{i}-w_{i}\right|
$$

where $x_{\mathrm{i}}$ and $w_{\mathrm{i}}$ are the components of the diameter distributions $X$ (optimal) and $W_{\circ}$ (stable), scaled to 1 (i.e., $\Sigma x_{\mathrm{i}}=\Sigma w_{\mathrm{i}}$ - Keyfitz 1968). The maximum value of $\Delta$ is 1 , and the minimum of o occurs when the diameter distributions $X$ and $W_{\circ}$ (scaled to 1) are identical. Smaller values of $\Delta$ result when the distributions $X$ and $W_{\text {o }}$ (scaled to 1 ) become more similar.

\section{Stumpage value model}

The stumpage value model applied in this study comes from López et al. (2013). It is a generalization of the model proposed for site index 20 in López et al. (2010) for Pinus nigra in the Spanish Iberian System. In Tab. 3, we provide the stumpage values we used to obtain the economic data (Montero et al. 1992, Trasobares \& Pukkala 2004). The regression models adjusted to these data appear in Fig. 2. The stumpage prices of Pinus nigra in Spain remained fairly stable between 1994 and 2011 (MAGRAMA 2012).

The last row in Tab. 3 shows the average price per cubic meter for trees belonging to the different diameter classes. This price is obtained by adding up the four rows above showing the contributions to the final value of a tree of the four industrial destinations according to the percentage of wood of each diameter class going into each product type. The prices of particle
Tab. 3 - Stumpage prices $\left(€ \mathrm{~m}^{-3}\right)$ of Pinus nigra in Spain according to its diameter class and industrial destination.

\begin{tabular}{lccc}
\hline \multirow{2}{*}{ Products } & \multicolumn{3}{c}{ Diameter classes $(\mathrm{cm})$} \\
\cline { 2 - 4 } & $<\mathbf{2 0}$ & $\mathbf{2 0 - 4 0}$ & $>\mathbf{4 0}$ \\
\hline Particle & 6 & 1.2 & 0.6 \\
Poles & 0 & 11.85 & 0 \\
Sawlog & 0 & 9.8 & 11.76 \\
High-quality sawlog & 0 & 0 & 9.96 \\
\hline Total average price & 6 & 22.85 & 22.32 \\
\hline
\end{tabular}

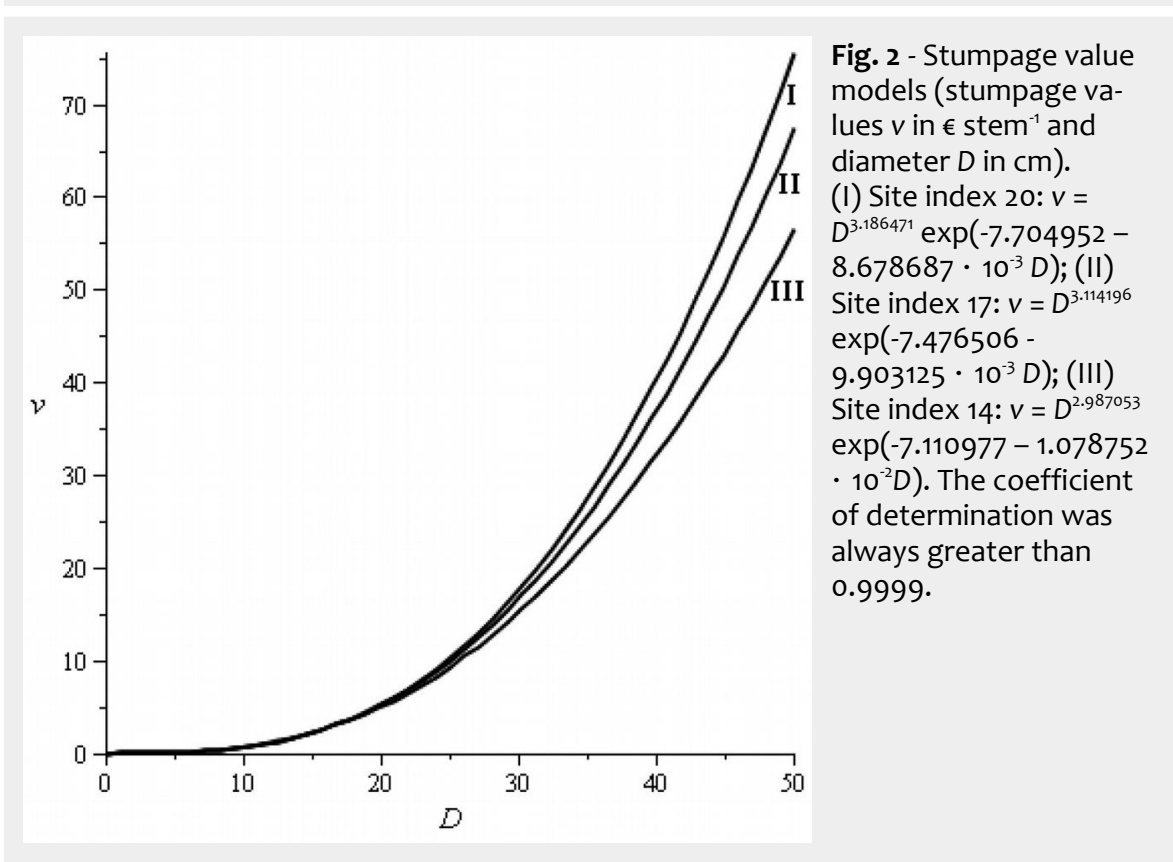

board, poles, sawlog, and high-quality the stable diameter distributions $W_{\mathrm{o}}$ in Tab. sawlog are 6.0, 39.5, 19.6, and $33.2 € \mathrm{~m}^{-3}, 2$ were replaced into the proposed discrete respectively. It is necessary to point out optimal control model. Global optimal soluthat the demand for timber poles in Spain tions to each corresponding optimization is very high and therefore they reach a problem were found using Solver ${ }^{\circledR}$ by chanhigher price than larger size sawlogs.

\section{Results}

The transition probabilities in Tab. 1 , the and the control variables $h_{\mathrm{k}}(t)$; basal areas "sustainable/stable" harvest rates $s$, and before and after each harvest; optimal NPV

\begin{tabular}{|c|c|c|c|c|c|c|c|c|}
\hline \multirow[b]{2}{*}{ Site Index } & \multirow[b]{2}{*}{$G$} & \multirow[b]{2}{*}{ Strategy } & \multicolumn{2}{|c|}{$R=200$ stems ha $^{-1}$} & \multicolumn{2}{|c|}{$R=520$ stems ha $^{-1}$} & \multicolumn{2}{|c|}{$R=840$ stems ha $^{-1}$} \\
\hline & & & $\begin{array}{l}\text { Value } \\
\left(€ \mathrm{ha}^{-1}\right)\end{array}$ & $\begin{array}{c}\text { Increase } \\
\text { (\%) }\end{array}$ & $\begin{array}{l}\text { Value } \\
\left(€ h a^{-1}\right)\end{array}$ & $\begin{array}{c}\text { Increase } \\
(\%)\end{array}$ & $\begin{array}{l}\text { Value } \\
\left(€ h a^{-1}\right)\end{array}$ & $\begin{array}{c}\text { Increase } \\
\text { (\%) }\end{array}$ \\
\hline \multirow[t]{6}{*}{20} & 22 & Sust/Stable & 5347.3646 & 12.48 & 6118.0328 & 14.33 & 6383.5522 & 14.43 \\
\hline & & Max. NPV & 6014.7773 & & 6994.8646 & & 7304.4446 & \\
\hline & 24 & Sust/Stable & 5743.3336 & 12.24 & 6611.1260 & 14.36 & 6918.9460 & 14.35 \\
\hline & & Max. NPV & 6446.4525 & & 7560.6334 & & 7911.8264 & \\
\hline & 26 & Sust/Stable & 6130.4531 & 11.93 & 7096.2876 & 14.35 & 7447.4339 & 14.32 \\
\hline & & Max. NPV & 6861.7018 & & 8114.2591 & & 8514.1776 & \\
\hline \multirow[t]{6}{*}{17} & 22 & Sust/Stable & 4239.2159 & 9.69 & 4986.6137 & 12.75 & 5284.1332 & 13.84 \\
\hline & & Max. NPV & 4649.9201 & & 5622.2967 & & 6015.6138 & \\
\hline & 24 & Sust/Stable & 4542.7283 & 9.31 & 5373.9477 & 12.61 & 5710.9061 & 13.65 \\
\hline & & Max. NPV & 4965.6346 & & 6051.5239 & & 6490.3456 & \\
\hline & 26 & Sust/Stable & 4838.9236 & 8.97 & 5754.1367 & 12.51 & 6131.0587 & 13.44 \\
\hline & & Max. NPV & 5272.7622 & & 6473.7901 & & 6955.3522 & \\
\hline \multirow[t]{6}{*}{14} & 22 & Sust/Stable & 3202.5660 & 6.20 & 3906.4753 & 10.12 & 4224.8230 & 11.44 \\
\hline & & Max. NPV & 3401.1319 & & 4301.8564 & & 4708.1096 & \\
\hline & 24 & Sust/Stable & 3421.6868 & 5.77 & 4194.9510 & 9.74 & 4548.7650 & 11.36 \\
\hline & & Max. NPV & 3619.2075 & & 4603.4830 & & 5065.3056 & \\
\hline & 26 & Sust/Stable & 3635.0537 & 5.36 & 4477.2298 & 9.39 & 4866.5857 & 11.27 \\
\hline & & Max. NPV & 3829.9429 & & 4897.7062 & & 5415.2350 & \\
\hline
\end{tabular}

Tab. 4 - NPV values ( $€$ ha"-1 $^{-1}$ for the "sustainable/stable" and the optimal harvesting strategies (Max. NPV) and NPV increase (\%) for $i=$ $3 \%$, and different levels of site index, $R$, and $G\left(G\right.$ in $\mathrm{m}^{2}$ ha" $)$. 
Fig. 3 - Population dynamics $x_{k}$ to maximize the NPV function throughout a harvest cycle of 70 years for $G=24 \mathrm{~m}^{2} \mathrm{ha}^{-1}$ and $i=3 \%$ (left: Site index 20; middle: Site index 17; right: Site index 14; first row: $R=$ 200 stems ha ${ }^{-1}$; second row: $R=520$ stems ha ${ }^{-1}$; third row: $R=840$ stems ha $\left.{ }^{-1}\right)$. The initial and final conditions are defined by the stable diameter distributions.

Fig. 4 - Optimal harvesting strategies $h_{\mathrm{k}}(t)$ for $G=24 \mathrm{~m}^{2} \mathrm{ha}^{-1}$ and $i=3 \%$ (left: Site index 20; middle: Site index 17; right: Site index 14; first row: $R=200$ stems ha $^{-1}$; second row: $R=520$ stems ha ${ }^{-1}$; third row: $R=840$ stems ha-1). The dashed lines depict the "sustainable/stable" harvest rates s.
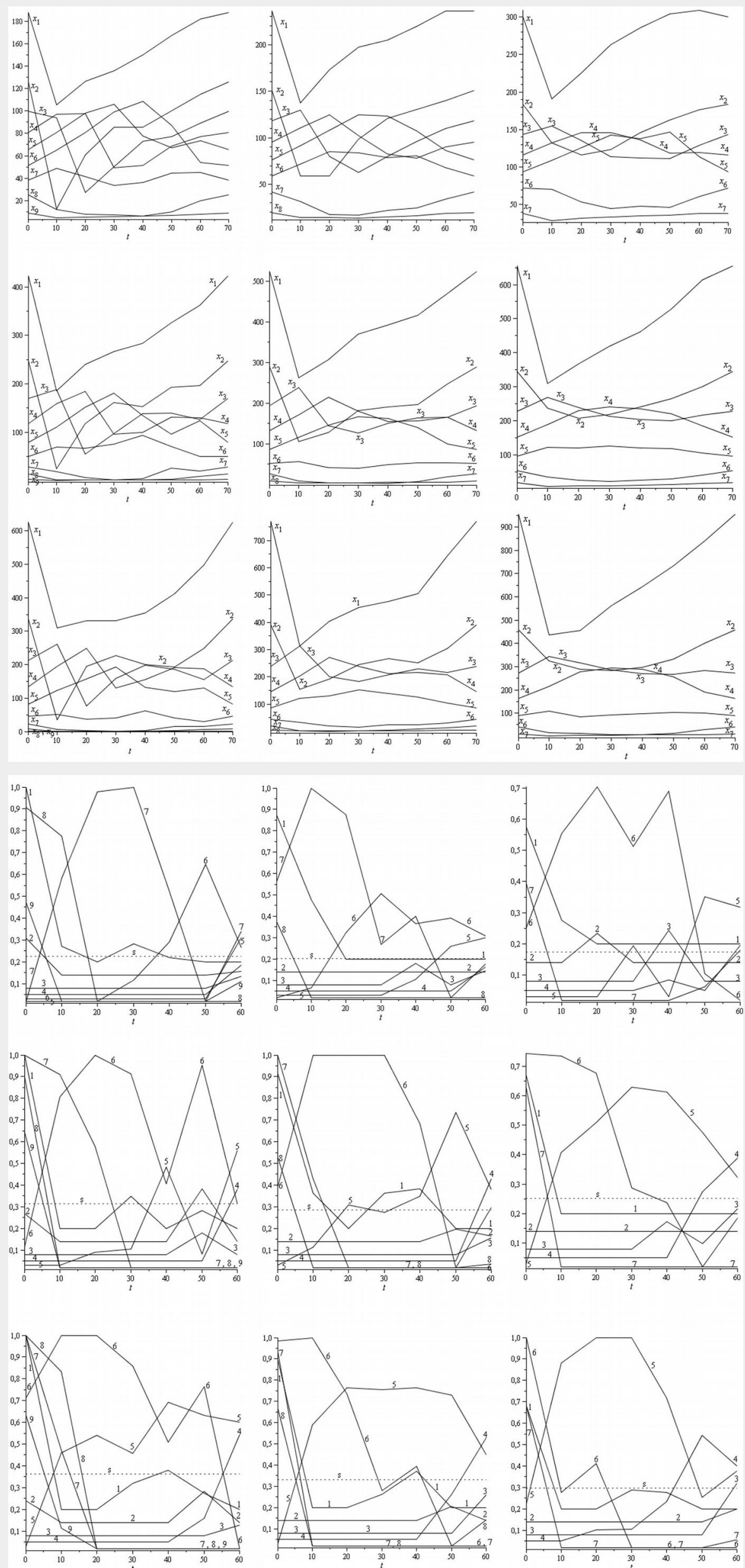
and the NPV corresponding to the "sustainable/stable" harvesting strategy; and Keyfitz's $\Delta$ for all of the scenarios considered. The discount rates applied fell between $2 \%$ and $4 \%$, as is typical of forest management studies.

The main results may be summarized as follows: (a) Fig. 3 shows the population dynamics $x_{\mathrm{k}}$ needed to maximize the NPV function over 70 years with $G=24 \mathrm{~m}^{2} \mathrm{ha}^{-1}$ and $i=3 \%$; (b) Fig. 4 depicts the optimal harvesting strategies $h_{\mathrm{k}}(t)$ for $G=24 \mathrm{~m}^{2} \mathrm{ha}^{-1}$ and $i=3 \%$; (c) the NPV values and the NPV increase between the "sustainable/stable" harvesting strategy $s$ and the optimal harvesting strategy (maximizing NPV function) for $i=3 \%$ and different values of site index, $R$ and $G$ are displayed in Tab. 4; (d) Tab. 5 shows the set of values for Keyfitz's $\Delta$ that correspond to the distance between the diameter distribution associated with the optimal harvesting strategy (for $t=70$ years) and the stable diameter distribution $\left(W_{0}\right)$ for every period of the planning horizon. It is worth to notice that the values obtained were always very low and yielded $\Delta=0$ for $t=0$ and $t=70$, as expected. Moreover, it should be stressed that the transition matrix $A_{\mathrm{T}}$ for the whole harvest cycle from $t=0$ to $t=70$ years is the following (eqn. 12):

$$
A_{T}=\prod_{t=T-10}^{t=0} A[I-H(t)]
$$

and that $\lambda_{\mathrm{T}}=1$ for all of the scenarios, where $\lambda_{T}$ denotes the population growth rate for the whole harvest cycle of $T=70$ years. Thus, considering the whole harvest cycle, these optimal harvesting strategies are sustainable. In addition to that, the stable diameter distribution is recovered at the end of the harvest cycle.

The optimal harvesting strategy aimed at maximizing NPV subject to the initial and final stage conditions $\left[X(0)=X(T)=W_{0}\right]$, results in higher NPV figures than the "sustainable/stable" conditions. For $i=3 \%$, this increment was always over $5.36 \%$ and reached a maximum of $14.43 \%$ for site index 20, $R=840$ stems ha $^{-1}$ and $G=22 \mathrm{~m}^{2}$ ha $^{-1}$. The NPV increase was greater for site index 20 than for site index 17 and site index 14 .

The influence of small variations in the discount rate or the natural mortality rates on the optimal harvesting strategies was minimal because they did not change the general pattern of the solutions found.

\section{Discussion and conclusions}

This study proposes a model that combines an objective function comprising the NPV of all the management operations in a planning horizon of $T=70$ years with a matrix model for the population dynamics, constrained in the initial and final states to be the stable diameter distribution of the stand, i.e., $X(0)=X(T)=W_{0}$. The resulting discrete optimal control model provides a simple tool for heuristic analysis to answer the "what if" questions in relation to forest management plans.

Tab. 5 - Set of values for Keyfitz's $\Delta$ corresponding to the distance between the diameter distribution associated with the optimal harvesting strategy and the stable diameter distribution (given by $W_{0}$ ) for every period of the planning horizon (note that $\Delta=$ 0 for $t=0$ and $t=T=70$ ).

\begin{tabular}{|c|c|c|c|c|c|}
\hline Site Index & $G$ & Year & $\begin{array}{c}R=200 \\
\text { stems ha }\end{array}$ & $\begin{array}{c}R=520 \\
\text { stems ha }^{-1}\end{array}$ & $\begin{array}{c}R=840 \\
\text { stems ha }{ }^{-1}\end{array}$ \\
\hline \multirow[t]{18}{*}{20} & 22 & 10 & 0.2504 & 0.3052 & 0.3164 \\
\hline & & 20 & 0.2374 & 0.2609 & 0.2422 \\
\hline & & 30 & 0.1864 & 0.1775 & 0.1704 \\
\hline & & 40 & 0.1433 & 0.1502 & 0.1777 \\
\hline & & 50 & 0.0875 & 0.0939 & 0.1505 \\
\hline & & 60 & 0.0364 & 0.0829 & 0.0986 \\
\hline & 24 & 10 & 0.25 & 0.3261 & 0.3195 \\
\hline & & 20 & 0.2377 & 0.2705 & 0.2433 \\
\hline & & 30 & 0.19 & 0.1806 & 0.1597 \\
\hline & & 40 & 0.1473 & 0.1432 & 0.1712 \\
\hline & & 50 & 0.0889 & 0.0836 & 0.1409 \\
\hline & & 60 & 0.0332 & 0.0794 & 0.1025 \\
\hline & 26 & 10 & 0.2356 & 0.3176 & 0.3247 \\
\hline & & 20 & 0.2365 & 0.2685 & 0.2455 \\
\hline & & 30 & 0.1882 & 0.1815 & 0.1565 \\
\hline & & 40 & 0.1512 & 0.1553 & 0.1655 \\
\hline & & 50 & 0.0888 & 0.095 & 0.132 \\
\hline & & 60 & 0.0331 & 0.0762 & 0.1044 \\
\hline \multirow[t]{18}{*}{17} & 22 & 10 & 0.2002 & 0.2585 & 0.2785 \\
\hline & & 20 & 0.194 & 0.1997 & 0.2175 \\
\hline & & 30 & 0.1588 & 0.1588 & 0.188 \\
\hline & & 40 & 0.1088 & 0.1235 & 0.1623 \\
\hline & & 50 & 0.081 & 0.1007 & 0.1489 \\
\hline & & 60 & 0.0306 & 0.0576 & 0.0718 \\
\hline & 24 & 10 & 0.1882 & 0.2512 & 0.2843 \\
\hline & & 20 & 0.1912 & 0.1992 & 0.2168 \\
\hline & & 30 & 0.1553 & 0.1571 & 0.1669 \\
\hline & & 40 & 0.1083 & 0.1238 & 0.1435 \\
\hline & & 50 & 0.0804 & 0.1013 & 0.1423 \\
\hline & & 60 & 0.0319 & 0.0535 & 0.0691 \\
\hline & 26 & 10 & 0.1744 & 0.2457 & 0.2803 \\
\hline & & 20 & 0.1854 & 0.2029 & 0.2149 \\
\hline & & 30 & 0.1549 & 0.1564 & 0.1661 \\
\hline & & 40 & 0.1099 & 0.1246 & 0.1333 \\
\hline & & 50 & 0.0794 & 0.1016 & 0.1316 \\
\hline & & 60 & 0.0329 & 0.0494 & 0.0721 \\
\hline \multirow[t]{18}{*}{14} & 22 & 10 & 0.1245 & 0.1923 & 0.1985 \\
\hline & & 20 & 0.1234 & 0.1881 & 0.2135 \\
\hline & & 30 & 0.1183 & 0.1636 & 0.1754 \\
\hline & & 40 & 0.0875 & 0.1311 & 0.136 \\
\hline & & 50 & 0.0801 & 0.0907 & 0.1072 \\
\hline & & 60 & 0.0358 & 0.0401 & 0.0482 \\
\hline & 24 & 10 & 0.1201 & 0.1889 & 0.1968 \\
\hline & & 20 & 0.1146 & 0.184 & 0.2063 \\
\hline & & 30 & 0.1116 & 0.1569 & 0.1756 \\
\hline & & 40 & 0.0837 & 0.1233 & 0.1441 \\
\hline & & 50 & 0.0768 & 0.0864 & 0.1026 \\
\hline & & 60 & 0.0349 & 0.037 & 0.0457 \\
\hline & 26 & 10 & 0.1141 & 0.1851 & 0.199 \\
\hline & & 20 & 0.1059 & 0.18 & 0.2094 \\
\hline & & 30 & 0.1049 & 0.151 & 0.1893 \\
\hline & & 40 & 0.0848 & 0.1165 & 0.1473 \\
\hline & & 50 & 0.0742 & 0.084 & 0.1002 \\
\hline & & 60 & 0.0339 & 0.0377 & 0.0448 \\
\hline
\end{tabular}

Following López et al. (2007, 2008, 2012, 2013), we calculated the transition probabilities considering that $p_{\mathrm{k}}$ is an average global property shared by all of the individuals in the same class $k$, and that, given the basal area constraints and the low basal area scenarios of this study, stand density has a small influence on diameter growth. Moreover, in the case of constrained optimization matrix models, in which the search for optimal paths throughout the phase space is mainly governed by the objective function, optimal decisions are essentially conditioned by the stumpage prices, i.e., by selective harvesting, and thus stand density has a minor influence on the objective function.

López et al. (2008) also show that results obtained for $\lambda_{0}$ are sensitive to the width $w$ of the diameter classes, such that the most conservative values of $\lambda_{0}$ and $s$ result from the lowest values of $w$, which does not allow an individual tree to jump over more than one diameter class in a single projec- 
tion. The minimum (integer) widths of the diameter classes compatible with this model assumption were $w=6 \mathrm{~cm}$ for site index 20, $w=5 \mathrm{~cm}$ for site index 17, and $w=$ $4 \mathrm{~cm}$ for site index 14 . However, because the dominant eigenvalue $\lambda_{0}$ and the stable diameter distribution are not substantially affected by small or even moderate changes in the width of the diameter classes (López et al. 2008), we assumed a width of $w=6 \mathrm{~cm}$ for our study to facilitate the comparison and presentation of results.

As shown in Tab. 4, the NPV increase between the optimal and the "sustainable/stable" harvesting strategies was related to site quality. The highest NPV increments in absolute terms were obtained for the scenarios corresponding to site index 20, $G=26$ and high to medium recruitment ( $R$ of 840 and 520 stems ha ${ }^{-1}$ ). Those increments were over $1000 €$ ha $^{-1}$, with NPV values for the optimal strategies over $8000 €$ $\mathrm{ha}^{-1}$. However, the NPV increase in relative terms lies between $5.36 \%$ and $14.43 \%$, showing a higher increase for higher quality sites and higher recruitments. For site index 20 and $R$ between 520 and 840 stems $\mathrm{ha}^{-1}$, the NPV increase was always over $14 \%$. For high quality sites, the highest relative advance on the NPV between the optimal harvesting strategy and the "sustainable/ stable" is reached for medium and high recruitment ( $R$ between 520 and 840 stems $\mathrm{ha}^{-1}$ ), while for low-quality sites, this relative advantage is higher for high recruitment ( $R=840$ stems ha $\left.{ }^{-1}\right)$.

By applying the optimal harvesting strategies, the maximum value obtained for Keyfitz's $\Delta$ was 0.32 , with small deviations from the stable distribution throughout the harvest cycle. The highest $\Delta$ values were obtained for site index 20, $R=840$ and 520 stems ha ${ }^{-1}$. On the other hand, the lowest values of $\Delta$ were obtained for site index 14 , and $R=200$ stems ha ${ }^{-1}$ (with $\Delta$ always less than 0.125 ).

In low-quality sites, the optimal management strategy leads to stand distributions that are closer to the stable distribution over the planning horizon than in mediumor high-quality sites. On the other hand, it is in these high-quality sites where the relative increase in the NPV is higher.

Regarding the optimal harvesting strategy (see Fig. 3, Fig. 4), the harvest rates are low for the first four diameter classes throughout the planning horizon. As expected, harvests for the seventh and eighth diameter classes are higher at the beginning of the planning horizon and lower during the last three periods. Most harvests for the fifth and sixth diameter class take place along the planning horizon. For medium and high recruitments, the highest harvest at the end of the planning horizon $(t=60)$ is performed mainly on the fourth and fifth diameter classes.

It is interesting to note that the optimal harvesting strategy results in a reasonable harvesting schedule, which follows from the dynamics of the stand, initial and final conditions, and the time preference stated by the NPV function, and that the NPV values obtained for the optimal harvesting strategies from this study lie always between those of the optimal (but not sustainable) harvesting strategies shown in López et al. (2013), where no restrictions were introduced for the final state, and the NPV values for the "sustainable/stable" harvesting strategy.

In conclusion, the proposed optimization model was used in this study to determine economically optimal harvesting strategies of uneven-aged Pinus nigra stands in the Spanish Iberian System, when the population dynamics are governed by a matrix model, the initial and final diameter distributions are constrained to be the stable diameter distribution $\left[X(0)=X(T)=W_{0}\right]$, and a set of constraints is stated to maintain the stand basal area within narrow ranges commonly used in the management of this species. Under such conditions, this study shows that there are sustainable harvesting strategies that retain the stable diameter distribution of the stand at the end of the planning horizon, yielding a higher NPV than the "sustainable/stable" scenario, especially for high-quality sites, although these NPVs are lower than the corresponding values for the economically optimal harvesting strategies.

\section{References}

Buongiorno J, Michie BR (1980). A matrix model of uneven-aged forest management. Forest Science 26: 609-625. [online] URL: http://www. ingentaconnect.com/content/saf/fs/1980/0000 0026/00000004/arto0018

Caswell H (2001). Matrix population models: construction, analysis, and interpretation $\left(2^{\text {nd }} e d n\right)$. Sinauer Associates Inc., Sunderland, MA, USA, pp. 710.

Gómez Loranca JA (1998). Modelo de crecimiento y producción para Pinus nigra Arn. en el Sistema Ibérico. [Growth and yield model for Pinus nigra Arn. in the Iberian System]. Montes Revista de Ámbito Forestal 54: 5-18. [in Spanish] Grande MA, García Abril A (2005). Los pinares de Pinus nigra Arn. en España: ecología, uso y gestión. [The forests of Pinus nigra Arn. in Spain: ecology, use and management]. Fundación Conde del Valle de Salazar - FUCOVASA, Madrid, Spain, pp. 699. [in Spanish]

Haight RG (1985). A comparison of dynamic and static economic models of uneven-aged stand management. Forest Science 31 (4): 957-974. [online] URL: http://www.ingentaconnect.com/ content/saf/fs/1985/00000031/00000004/artoo 025

Keyfitz N (1968). Introduction to the mathematics of population. Addison-Wesley, Reading, MA, USA, pp. 450.

Kronrad GD, Huang CH (2002). Financially optimal thinning and final harvest schedules for loblolly pine plantations on nonindustrial private forestland in east Texas. Southern Journal of Applied Forestry 26 (1): 13-17. [online] URL: http://www.ingentaconnect.com/content/saf/sj af/2002/00000026/00000001/arto0003

Liang J, Picard N (2012). Matrix model of forest dynamics: an overview and outlook. Forest Science 59 (3): 359-378. - doi: 10.5849/forsci.11-123 López I, Ortuño S, Martín AJ, Fullana C (2007). Estimating the sustainable harvesting and the stable diameter distribution of European beech with projection matrix models. Annals of Forest Science 64: 593-599. - doi: 10.1051/forest:20070 37

López I, Fullana C, Ortuño SF, Martín AJ (2008). Choosing Fagus sylvatica L. matrix model dimension by sensitivity analysis of the population growth rate with respect to the width of the diameter classes. Ecological Modelling 218: 307-314. - doi: 10.1016/j.ecolmodel.2008.07.007 López I, Ortuño S, Martín A, Fullana C (2010). Estimating the optimal rotation age of Pinus nigra in the Spanish Iberian System applying discrete optimal control. Forest Systems 19 (3): 306-314. - doi: 10.5424/fs/2010193-8560 López I, Ortuño S, García F, Fullana C (2012). Is De Liocourt's distribution stable? Forest Science 58 (1): 34-46. - doi: 10.5849/forsci.10-015

López I, Ortuño S, García F, Fullana C (2013). Are the economically optimal harvesting strategies of uneven-aged Pinus nigra stands always sustainable and stabilizing? Forests 4: 830-848. doi: $10.3390 / f 4040830$

MAGRAMA (2012). Boletín mensual de estadística 1994-2011. [Monthly statistical bulletin 1994-2011]. Technical General Secretary of the Spanish Ministry of Agriculture, Food and Environment, Madrid, Spain, pp. 48. [in Spanish] Maple (2014). Maplesoft version 18.o. Waterloo Maple Inc., Ontario, Canada. [online] URL: http://www.maplesoft.com/products/maple/ Misir M, Misir N, Yavuz H (2007). Modeling individual tree mortality for Crimean pine plantations. Journal of Environmental Biology 28 (2): 167-172. [online] URL: http://jeb.co.in/journal_is sues/200704_apro7/paper_03.pdf

Montero G, Rojo A, Alía R (1992). Determinación del turno de Pinus sylvestris L. en el Sistema Central. [Determination of rotation age for Pinus sylvestris L. in the Central System]. Revista Montes 29: 42-47. [in Spanish]

Retana J, Espelta JM, Habrouk A, Ordóñez JL, Solà-Morales F (2002). Regeneration patterns of three Mediterranean pines and forest changes after a large wildfire in north-eastern Spain. Ecoscience 9: 89-97. [online] URL: http://www.jstor.org/stable/42901389

Richards FJ (1959). A flexible growth function for empirical use. Journal of Experimental Botany 10 (29): 290-300. - doi: 10.1093/jxb/10.2.290

Schütz JP (1989). Le regime du jardinage [The gardening regime]. Chaire de sylviculture, ETH Zürich, Switzerland, pp. 110. [in French]

Schütz JP (2006). Modelling the demographic sustainability of pure beech plenter forests in Eastern Germany. Annals of Forest Science 63: 93-100. - doi: 10.1051/forest:2005101

Serrada R, Domínguez Lerena S, Sánchez Resco MI, Ruiz Ortiz J (1994). El problema de la regeneración natural de Pinus nigra Arn. [The problem of natural regeneration of Pinus nigra Arn.]. Revista Montes 36: 52-57. [in Spanish] Sethi SP, Thompson GL (2000). Optimal control theory: applications to management science and economics ( $2^{\text {nd }}$ edn). Kluwer Academic Publishers, Boston, MA, USA, pp. 505.

Siegel W, Hoover W, Haney H, Liu K (1995). Fo- 
rest owners' guide to the federal income tax. Agriculture Handbook No. 708, USDA Forest Service, Washington, DC, USA, pp. 138.

Tahvonen $\mathrm{O}$ (2004). Optimal harvesting of forest age classes: a survey of some recent results. Mathematical Population Studies 11: 205-232. doi: $10.1080 / 08898480490513616$

Tíscar PA (2007). Dinámica de regeneración de Pinus nigra subs. Salzmannii al sur de su área de distribución: etapas, procesos y factores implicados. [Regeneration dynamics of Pinus nigra subs. Salzmannii south of its distribution area: stages, processes and related factors]. Investigación Agraria: Sistemas y Recursos Forestales
16(2): 124-135. - doi: 10.5424/srf/2007162-01003 Tíscar Oliver PA, Lucas ME, Tíscar Soria MA (2010). La alteración del suelo y la espesura como factores de regeneración de Pinus nigra subs. Salzmannii a lo largo de su área de distribución. [Soil alterations and stem density as regeneration factors for Pinus nigra subs. Salzmannii along its distribution area]. Revista Montes 103: 10-15. [in Spanish]

Trasobares A, Pukkala T (2004). Optimising the management of uneven-aged Pinus sylvestris $L$. and Pinus nigra Arn. mixed stands in Catalonia, north-east Spain. Annals of Forest Science 61: 747-758. - doi: 10.1051/forest:2004071
Van Mantgem PJ, Stephenson NT (2005). The accuracy of matrix population model projections for coniferous trees in the Sierra Nevada, California. Journal of Ecology 93: 737-747. - doi: 10.1111/j.1365-2745.2005.01007.x

Vanclay JK (2012). Modelling continuous cover forests. In: "Continuous cover forestry" (Pukkala T, Gadow KV eds). Managing Forest Ecosystems 23, Springer, Berlin, Germany, pp. 229241. - doi: 10.1007/978-94-007-2202-6_7 Von Bertalanffy L (1938). A quantitative study of organic growth (Inquiries on growth laws, II). Human Biology 10: 181-213. 